\title{
The bullying phenomenon and the "I am not scared" project in Bulgaria or how and why we need to influence the national school-education system
}

\author{
Zornitsa Staneva* and Miglena Molhova \\ Zinev Art Technologies, Bulgaria
}

(Received September 15, 2011; Accepted October 17, 2011)

\begin{abstract}
Violence in schools has been recognized as a growing and destructive problem both by educational and policy making authorities at a national level, as well as by the European Commission at an EU level. The graveness of the problem, some of its roots, because they can vary greatly from country to country, has already been analyzed and there are numerous proposals and programs for tackling with the problem or preventing its appearance. Still, political decisions and changes need to be encouraged in order to enforce, to make practicing from proposals and programs obligatory and official. These changes should and could happen in both directions - starting from the national level and reaching out to the Community level, or vice versa. The current and future effects for the Bulgarian school education system of a project - "I am not scared" - supported by the EC under the Lifelong Learning Program are briefly outlined in the present article.
\end{abstract}

Keywords: violence, aggression, harassment, prevention, cyber bullying, national policies of bullying prevention.

El fenómeno del bullying y el proyecto "Yo no tengo miedo" en Bulgaria, o cómo y por qué tenemos que influir en el sistema educativo nacional

RESUMEN: La violencia escolar ha sido reconocida como un problema creciente y destructivo tanto por las autoridades educativas en un nivel nacional, como por la Comisión Europea a un nivel europeo. La gravedad del problema, algunas de sus causas, que pueden variar de modo significativo en función del país, han sido ya analizadas y hay numerosas propuestas y programas para combatir el fenómeno o prevenir su aparición. Sin embargo, aún es necesario estimular el desarrollo de medidas políticas que posibiliten que estas iniciativas tengan un carácter generalizado. Estos cambios pueden y deben ocurrir en dos direcciones: comenzando en un plano nacional que se extienda a las distintas regiones y viceversa. Los efectos presentes y futuros del proyecto "I Am Not Scared", financiado por la Comisión Europea dentro del programa Lifelong Learning, sobre las escuelas y el sistema educativo búlgaro se discuten brevemente en este artículo. Palabras clave: violencia, agresión, acoso, prevención, cyberbullying, políticas nacionales de prevención del bullying. 


\section{NATIONAL BACKGROUND}

Since the end of 2010 in Bulgaria started the implementation of the "I am not scared" project, addressing the bullying phenomenon on EU level. The project is supported by the Lifelong Learning Program (KA1 Policy Cooperation and Innovation) and it intends to identify the best European strategies to prevent and combat bullying.

In order for the relevance of this action to the national school-education situation to be fully comprehended, we will try to present a brief description of the changes in society, which took place on the grounds of an array of political, social, economic and personal values changes, which took place locally and globally.

In the world that surrounds us and which we live in more and more dynamically but also more and more anxiously, we face various manifestations of aggression and violence. Sometimes acts of arrogance and disrespect leading to brut physical or otherwise - verbal, psychological or sexual violence have become conscious style of behavior and way of "coping with stress", resolving the internal psychological anguish or releasing complexes or an "effective tool" for resolving interpersonal conflicts.

The links between family, school and society are broken or are not yet fully built in order to function adequately to new social realities and challenges. The complex processes through which our society has been going through for 22 years (after the changes of the political regime in 1989) now have not led to the formation of a "working" civil society, to the establishment of areas (fields) of influence, capable of self-regulation. The change in our society had to create new values, to restructure our value system, while preserving the best of old and adding new elements. However, this was an impossible task. Society suffers from a lack of stable values and ideals of adequate social reality. While struggling for survival and dealing with the harshness of the new social order, raising and educating a new generation seemed to have stayed in the background. With the deepening of the socio - economic crisis in society the growth of domestic violence is rising. In this context, unemployment and lack of financial security may be identified as the main factors triggering violence in all its forms. This systematic and uncontrollable violence at macro social level has very strong and seriously erosive impact at micro social level - it determines the patterns of gross and violent behavior in interpersonal relationships and cultivates certain stereotypes and patterns of behavior in the minds of young people. Permanent demonstration in social terms, that the rough man is stronger, that brazen man succeeds, that in the world and society arrogant brute force prevails and the one who succeeds in life is only the one who boldly, decisively and courageously violates generally accepted norms and rules, affects the formation of young minds and affects their education. This forms lasting attitudes which have cognitive, emotional and volitional element - they are both worldviews stereotypes and a role model and behavior.

Observations on life, as well as data from a study made in Bulgaria from the 
National Center for Observation of the Public Opinion, show that in size and cruelty domestic violence is dominant. Domestic violence is usually provoked not by the fact that the child has failed to follow the parent's requirements, but by the fact that the family has a problem. $49,2 \%$ of the respondents consider that domestic violence is a personal problem, while 50,8\% think it is a problem of society. It is interesting to point out that mostly young people (under the age of 30) and elderly people (over 60 years) consider this to be a personal problem (Makeva, 2009). To pass from verbal communication to the arrogant and brutal forms of aggressive behavior and violence is now like a very deliberate and rational strategy adopted to achieve one's goals and aspirations in life. Strategy, which is passed from adults on to children as a behavioral model - to children, who being fragile in its spiritual and moral consciousness imitate mechanically or apply this style of behavior in relationships with peers without restraint. What emerges as a fact from these acts of aggression is that in most cases aggressors and authors of the acts are teenagers who are motivated and driven in their actions by special aversion to victims mixed with envy, jealousy, competition or competitive desire for self improvement and demonstration of superiority, by attempts of domination over and humiliation of the weaker.

Modern environmental factors that increase the tendency for the exercising of violence in our country can be grouped as follows (Bulgarian Ministry of Internal Affairs, 2007):

- Socio - economic crisis and its consequences - a factor, which threatens the physical survival of individuals or families and causes spiritual disillusionment;

- The media - a factor, which threatens the building of values in adolescents and in a sense, provokes the use of violence as a mechanism for resolving conflicts;

- Globalization - a factor, which threatens the self-realization of personality. In a global society man realizes his imperfection and more often falls into depression;

- Alienation - a factor, which threatens the cohesiveness of the community as a group and provokes mistrust and insecurity;

- Social devaluation - a factor, which threatens the preservation of spiritual identity. The lack of values and value orientation affects humankind predominantly regressively.

As the main risks in a family environment that lead to aggressive behavior by children we can point out (Petrov, 2000):

- $\quad$ Lack of parental love, care and attention;

- Dissolution of marriage;

- Incomplete families;

- "Step" families; 
- Alcoholism and drug addiction of parents;

- Low cultural and educational level of parents;

- Sexual abuse of children;

- Self-centered parents;

- Bisexual parents;

- Economic problems in the family;

- Unlawful conduct by parents;

- Social, legal and national nihilism, transmitted from parents to children.

In the process of socialization along with family and school influence a significant role in the shaping of the behavioral pattern of the child plays its environment. According to the accepted group mechanisms, informal peer group, consolidated on the basis of common interests and leisure activities, is a territory of mutual "contamination" with behavioral stereotypes. When a negative deviation from the norm is part of the group policy, it directly impairs the socialization of its individual members, as the duplication of the model by each of them enhances its acceptance by the others. Part of the reference environment is communication with significant adults or older children who are not part of the family. School and the environment of friends produce risks when they are dysfunctional and evertime they are absent. As risks of the school environment are regarded (Minev, 2001; Petrov, 2000):

- Placing unreasonably low grades;

- Undervaluing children's efforts and successes;

- Imposing unreasonable penalties;

- Entry into "elite" schools;

- Poor relations in the class team;

- Selection of "favorite" and "difficult" students by teachers;

- Decline in professional development and achieving high personal prestige from part of the teachers;

- Physical deficiencies of individual students;

- Lack or shortage of organized extracurricular activities;

- Negative relationships between teachers and parents;

- Limiting school functions to teaching - implicitly dropping the educational/behavioral aspects;

- Tolerance of unacceptable student behaviors;

- Atmosphere of insecurity in school districts;

- Absence of alternatives to deviant behavior;

- Difficulties in adaptation after changing the school.

The listed above micro social factors are combined with the overall value crisis in the Bulgarian society, which according to Minev can be summarized with the following characteristics (Minev, 2001, cited in Konstantinov \& Taushanov, 2001): 
- Collapse of traditional moral norms governing the overall relationship between people and personality. Saturation of moral space with individualism, selfishness, greed, self-seeking interest, corruption;

- Failure of regulators ensuring national and community interests; national nihilism, nationalism, social anomie; fading of the idea of patriotism;

- Collapse of moral standards governing the attitude towards labor and property; corruption, mismanagement, extortion, abuse of power; discredit of work and honesty in economic relations as a means of material prosperity;

- Failure of the rules governing the treatment of human relationships; apathy, insincerity, pettiness, plotting, wrongdoing;

- Collapse of moral norms governing relations between young men and women, marriage and family. Devaluation of love, levity in the sexual life, nihilistic attitude towards marriage;

- Collapse of the moral importance of training and education. All this creates an environment of social disorganization in which the young man should be built as a person.

\section{VIOLENCE IN BULGARIAN SCHOOLS IN FIGURES}

The phenomenon of bullying in Bulgarian schools is very widespread. According to a survey of the polling agency Alpha Research conducted in 2006 (Dimitrova, 2006) nearly 70\% of students admit that in their school there were cases of aggression. According to parents and children the poor family environment $(73 \%)$ and the lack of discipline at school $(68 \%)$ are among the main causes of aggression in school (Dimitrova, 2006). Data from the same survey show also that in general society has no respect for the Bulgarian school as an institution. And students (81\%) and parents (92\%) believe that the level of aggression in school is high. According to $63 \%$ of the adults, however, this trend has increased in recent years, while previously the cases of violence among children have been less. They say the reasons are poor family environment, lack of discipline in schools and material differences between the children. As a cause of violence among children and parents indicate computer games in which there is aggression, and the media showing violence. Half of parents and students believe that children who have shown aggression must be helped within the school. According to nearly $55 \%$ of parents and $37 \%$ of children in such cases the assistance of social institutions should be sought. Adults supported the return of the assessment of student behavior; the measure was supported by 89.5 percent of respondents, while young people are more against it.

Data from a study, performed by UNICEF, "The level of bullying in Bulgarian Schools" for 2007, show that $25 \%$ of children believe they are victims of bullying once a week or more often, while $10 \%$ of children admit that they harass their peers (UNICEF, 2007a). In each class, at least two children are bullied and three children show some form of aggression towards their classmates. Parado- 
xically, it appears that some of the consequences of harassment (and especially long term ones) are similar for bullies and victims. These include for example susceptibility to depression, difficulty in forming meaningful relationships with others, the probability of transmission through the generations, etc. It is more than obvious that we must give timely assistance to all affected by bullying and try to lead our children out from this vicious circle of repeated violence and suffering (Bonova, 2010).

UNICEF and the Society of Psychologists presented data on cyber violence among children in Bulgaria (UNICEF, 2007b). According to the survey 23\% of students aged 10-14 said they had been subjected to cyber-bullies at least once during the last academic year. Students aged 14 share that one third of bullying at school happens through mobile phones and the Internet. $13 \%$ of the students confessed that they have cyber-bullied another person at least once in the passed year, and 3\% say they are doing it every week. The most common forms of cyber-bullying are: release of gossip in social networks (56\% of cases); offensive calls over mobile phones (56\%); threatening SMS-s (49\%), placing false or obscene pictures (39\%) and others. Only $24 \%$ of the children "victims" have shared with their teachers that they are harassed. Most often this is shared with the mother but very few parents and teachers know what is cyber bullying and how they can cope with it. $29 \%$ the children say they do not share with anyone that they are bullied. Statistics show that only $15 \%$ of parents are familiar with the phenomenon of cyber-bullying. This requires a change in the way of communication not only among peers but also between children and their mothers and fathers. According to the psychologist Methodi Coralov (Bonova, 2010) the problem of bullying in Bulgaria is noticeable as early as in third graders, and one third of 10-year-olds consider cyber-bullying as something normal happening around them. The leading forms of bullying in the schoolyard are insults, inventing nicknames, ironic remarks and gossip, and almost all can seamlessly move into cyberspace (Bonova, 2010).

According to a study conducted under a joint project of the Applied Research and Communications Fund and Parents Association, supported by the Swiss foundation "Oak" and the "Safer Internet" by the European Commission in 2008 in 5 schools in Sofia, almost 76 percent of children in 5 to 12 grade had witnessed violence at school (Safer Internet Centre, 2009). Of the surveyed nearly 350 children $26.8 \%$ indicated that over the past four months they often witnessed violence at school, others $48.8 \%$ selected the answer "sometimes". About $78 \%$ of children indicate that during this period they have often seen violence on the TV, $72.6 \%$ - on the street, $59.5 \%$ - in the Internet, $27.4 \%$ - in mobile communications, and $10.4 \%$ witnessed violence at home. $35.1 \%$ of children admit that they themselves have participated in some form of violence at school. Of these, $18.8 \%$ indicated that they were more in the role of victim, $16.7 \%$ admit that they were more initiators and $58.6 \%$ were in the role of bystanders. About $30 \%$ of children were involved in violence on the streets, $22.6 \%$ - in the Internet, 14.9 $\%$ - in mobile communications, and $11.6 \%$ - in their own home. Only $65.5 \%$ 
of them say they know who to contact if they become victims of violence. Most protected from violence children feel at home $-81.8 \%$, next is in mobile communications with 39.9 percent, $30.7 \%$ of the respondents do not feel threatened in the Internet, $22.9 \%$ feel safe at school and only $11.9 \%$ feel safe on the street. Meanwhile, $54.8 \%$ of the students surveyed believe that the Internet is a dangerous place, as the three main threats they point out: meetings with unknown people - $11.5 \%$; computer viruses $-9.2 \%$ and theft of money from trick cards and to purchase goods - 7.7\% (Safer Internet Centre, 2009).

In the pilot study conducted by UNICEF in 2007 some issues related to trends and differences, age aspects of the forms of bullying that boys and girls prefer to use, and also what forms of abuse they most often have to tolerate are studied (UNICEF, 2007a):

\section{Differences and similarities between boys and girls}

- When they are the victims:

- Boys are more often subject to physical abuse;

- Girls are more often subject to indirect harassment;

- Girls receive assistance and support from others in greater extent;

- There is no difference in verbal harassment - boys and girls are approximately equally insulted, receive unpleasant nicknames, mocked at, threatened, etc.;

- Approximately equal number of boys and girls are bullied by their peers.

- When they are in the role of torturers:

- Boys more often resort to physical aggression;

- Boys have significantly higher levels of verbal aggression;

- Indirect aggression, which is traditionally considered more „feminine“ is actually as often used by girls and boys;

- Boys are almost twice as often in the role of tortures than the girls.

\section{Age characteristics}

\section{- With regard to victims}

The general trend is to report lower levels of experienced harassment with the increasing of age. Although this at first glance seems very optimistic, things really are not so positive. "Lower levels of harassment" means that fewer children are victims of malicious and regular aggressive action by other children. But this is not always true. Typically, children who enter in adolescence and puberty are keen to present themselves as mature and capable of dealing with problems in front others. For this reason they often do not want to admit even to themselves that others behave badly with them. And both for them and for the others, for whom the harassment lasts for years, the situation continues to be aggravated. 
They not only become accustomed to the role of victims, and have no idea how to get out of it, but are often bullied by other people or groups of torturers, who improve their skills to annoy, to torment, etc. on them.

\section{- With regard to torturers}

Both boys and girls use mostly verbal aggression, and this trend is not only maintained, but increases with time. Physical aggression in both sexes decreases slightly after the 8-9 grades. With girls from 4-5-6 grades there is no difference between physical and indirect aggression, but with the growing up the show clear preference for indirect aggression. Boys-torturers from early age are interested in all three forms of aggression and implement them (UNICEF, 2007a).

\section{NATIONAL POLICIES IMPLEMENTED TO PREVENT AND COMBAT THE BULLYING PHENOMENON}

A dedicated state policy on prevention of violence in schools is still missing in our country, despite of the actuality and acuteness of the problem. Despite the fact, the State Agency for Child Protection adopts each year a national program for child protection, which sets out priority areas of work. Preventing violence is one of the main priorities of the program within which a national helpline for children is developed; a national plan to prevent violence is adopted and a number of information campaigns are implemented.

In addition to the National Programme for Child Protection, each municipality, following the priority areas set by the program, develops its strategy for child protection. Within these local strategies numerous initiatives and projects specifically aimed at preventing violence in schools are implemented. The activities set out in the National Programme for Child Protection for 2011, will support the ongoing reforms in the areas of protection and support of children and family and help for the better coordination and implementation of sectoral policies to achieve more effective protection of fundamental rights of children in Bulgaria. Activities are structured in seven major areas - social policy, health, education, justice and judicial system; sports, culture, leisure, recreation, participation of children, information society and media. The implementation of the program envisages the development of a minimum package of services for family support (social, health, education, transport, etc.) and mechanism for their introduction in 2012 in all country regions.

\section{THE “I AM NOT SCARED” PROJECT IN BULGARIA}

The leader of consortium and promoter of the "I am not scared" concept is Istituto di Istruzione Superiore Don Lorenzo Milani, Italy. In its efforts and ideology it is being supported in Bulgaria by Zinev Art Technologies and 9 more partner organizations in different EU countires: INFOREF (Belgium), the School 
of Pedagogical and Technological Education (Greece), Zentrum für empirische pädagogische Forschung (zepf), Universität Koblenz-Landau (Germany), Connectis (Italy), Pixel (Italy), Kaunas University of Technology (Lithuania), EuroEd Foundation (Romania), the University of Seville (Spain) and the Wilsthorpe Community School (Great Britian).

The project intends to identify the best European strategies to prevent and combat the bullying phenomenon and involve secondary school and vocational education teachers, directors, pupils, parents and key policy makers in the field of education in a common reflection based on a bottom-up approach for a transnational sharing of the dynamics that can cause the emerging and consolidating of the bullying phenomenon and of the most effective strategies and behaviors to tackle it, available at European Level.

At the beginning of the "I am not scared" project we were not sure about the feedback, which we were about to obtain from potentially interested institutions, namely schools, public authorities, counselors, pedagogic advisors and psychologists. Now, after reaching a number of almost 20 schools throughout the whole country - interested and willing to join the project activities - and a strong group of regional educational inspectorates and local authorities, we are determined to achieve an impact, which would not only reverberate for a long time within the school educational system, but would urge the policy and decision makers to take action.

Compared to other initiatives held in Bulgaria to combat bullying the "I am not scared" project is different in several ways:

- The project involves different actors in the process of identifying and analyzing actions of bullying in school. Previous initiatives have paid attention on the points of view and consequences from the acts of bullying for the bully and the victim. While the project aims to gather all actors, who can play a role in combating bullying - not only the victims and bullies, but also teachers, administrative staff in school, psychologists, parents and last but not least decision and policy makers, responsible for policies for child's protection and education;

- The "I am not scared project" aims to explore the problem of bullying not only in the national context, but also in the EU context by comparing policies, strategies, initiatives and approaches;

- The project also aims at creating a platform, on which all the interested parties can exchange ideas and experience as to how to combat bullying at school;

- One of the best characteristics of the project is that it will involve the target groups in a discussion of real and hypothetical cases of bullying in order to get different points of view and create examples of best practices in comba- 
ting the problem.

Detailed presentation of all project developments and products can be found on the project portal: http://projects.pixel-online.org/iamnotscared/index.php

\section{CONCLUSIONS}

In Bulgaria the problem of bullying is very serious and yet political measures and dedicated strategies to combat it are still missing. There are some pilot initiatives in the country with regard to bullying prevention but not a consistent and coherent policy in the field. The project "I am not scared" is one initiative, which involves various actors in order to help the schools and policy and decision makers in the country to develop better solutions for prevention of violence and diminish the level of bullying in schools. So far the project managed to involve 44 teachers, 517 students, 316 parents, 12 counselors and 7 public authorities in Bulgaria. 50 publications with regard to bullying were reviewed in Bulgarian and English and uploaded in the project portal together with 11 good practices.

We can only hope that making the project available as a practice to a broad audience will make the Bulgarian authorities consider it in developing youth policies in the country and a targeted policy for preventing violence in schools will be elaborated, taking into account all the good initiatives, which have proven their effectiveness in the field and which were analyzed in the framework of the "I am not scared" project.

\section{REFERENCES}

Bonova, T. (2010). A survey about cyberbullying in Bulgaria. Retrieved from http://www.unicef.bg/bg/news/edna-treta-ot-nasilieto-sred-decata-e-v-kiberprostranstvoto

Bulgarian Ministry of Internal Affairs (2007). What is violence and how it is reached. in Annual report Ministry of internal affairs (pp. 2-3). Sofia.

Dimitrova, B. (2006). There is aggression in schools both children and parents say. Actualno, Web Ground. Retrieved from http://education.actualno.com/ news_85928.html

Konstantinov, E., \& Taushanov, K. (2001). Protection of child and the new century. Sofía: Goreks Press.

Makeva, Bl. (2009). Domestic violence in the Republic of Bulgaria - Researches and Facts. Annual report Ministry of internal affairs, 3-10

Minev, T. (2001). Anti-social behaviour of juveniles in the contemporary renewing world. Sofia: Spectra.

Petrov, G. (2000). Juvenile delinquency. Sofia: Abagar.

Safer Internet Centre (2009). Experts round table discusses safer Internet education in schools. Retrieved from http://www.safenet.bg/index. php?id=1387\&art_id=15373

UNICEF (2007b). Violence among children: what you need to know about it. 
Brochure for parents. Sofia: UNICEF.

UNICEF (2007b). One third of violence among children is in the cyberspace. Retrieved from http://www.unicef.bg/en/news/one-third-of-violence-amongchildren-is-in-the-cyberspace. 